\title{
MUDANÇAS CLIMÁTICAS E PROJETOS DE PRESTAÇÃO DE SERVIÇOS AMBIENTAIS EM TERRAS INDÍGENAS NO AMAZONAS ${ }^{1,2}$
}

\author{
Serguei Aily Franco de Camargo ${ }^{3}$ \\ Universidade Estadual de Roraima (UERR) \\ Plínio Henrique Oliveira Gomide ${ }^{4}$ \\ Universidade Estadual de Roraima (UERR) \\ Thaísa Rodrigues Lustosa de Camargo ${ }^{5}$ \\ Ministério Público do Estado do Amazonas
}

\section{RESUMO}

Devido à seca de 2005, o Amazonas editou a Lei n. 3.135, de 05 de junho de 2007, que instituiu a Política Estadual sobre Mudanças Climáticas. O texto previu formas de promoção do desenvolvimento sustentável, de manutenção das condições climáticas e incentivos à participação da população e do Estado na tutela ambiental. Entretanto, cerca de 10 anos após sua edição, a lei parece ter caído em desuso. Parte da ineficácia se deve ao desmantelamento da estrutura de Estado que atuava na implementação de seus instrumentos e parte, em virtude da falta de regulamentação complementar. Anos depois, o Amazonas editou a Lei n. 4.266, de 01 de dezembro de 2015, que instituiu o sistema de gestão de serviços ambientais no estado, criou o Fundo Estadual de Mudanças Climáticas e alterou as leis n. $3.135 / 2007$ e 3.184 de 13 de novembro de 2007, que por sua vez, também altera a

1 Pesquisa financiada pela CAPES/PNPD, período 2016/17.

2 Os autores agradecem ao Apoio da CAPES e do Programa de Pós-Graduação em Agroecologia da Universidade Estadual de Roraima. Agradecem também aos referees anônimos, pelas importantes contribuições ao texto originalmente apresentado

3 Pós-Doutorado em Ciências Sociais Aplicadas pela Universidade Estadual de Campinas (UNICAMP). Pós-Doutorado em Direito Ambiental pela Universidade Estadual Paulista Júlio de Mesquita Filho (UNESP). Pós-Doutorado em Ciências Biológicas pela UNICAMP. Doutorado em Aqüicultura pela UNESP. Mestrado em Conservação e Manejo de Recursos pela UNESP. Graduação em Direito pela UNESP. Professor na UERR. ORCID: http://orcid.org/0000-0003-1899-2311 / e-mail: sergueiaily@ mprr.mp.br

4 Doutorado em Ciência do Solo pela Universidade Federal de Lavras (UFLA). Mestrado em Ciência do Solo pela UFLA. Graduação em Agronomia pela UFLA. Professor na UERR. ORCID: http://orcid. org/0000-0002-2545-8195 / e-mail: pliniogomide@gmail.com

5 Doutorado em Ciências do Ambiente e Sustentabilidade na Amazônia pela Universidade Federal do Amazonas (UFAM). Mestrado em Direito Ambiental pela Universidade Estadual do Amazonas (UEA). Especialista em Direito e Processo do Trabalho e pela Universidade Anhanguera (UNIDERP) e em Pesquisa Educacional pela UEA. Gradução em Direito pela UEA. Assessora Jurídica do Ministério Público do Estado do Amazonas. ORCID: http://orcid.org/0000-0001-8800-6260 / e-mail: tatarlustosa@yahoo.com.br 
Lei n. 3.135/2007. Pretende-se assim, avaliar a interação entre todas essas normas, em um amplo exercício de interpretação, com o objetivo de constatar sua eficácia socioambiental. Concluiu-se que a participação das comunidades tradicionais em unidades de conservação de uso sustentável e dos povos indígenas em suas terras, enseja eficácia parcial à Lei 3.135/2007, ao permitir a implementação de projetos de redução das emissões por desmatamento e degradação nessas áreas protegidas, possibilitando o pagamento de recompensas aos prestadores de serviços ambientais.

Palavras-chave: Lei Estadual do Amazonas n. 3.135/2007; Lei Estadual do Amazonas n. 4.266/2015; mudanças climáticas; terras indígenas; Unidades de Conservação de Uso Sustentável.

\section{CLIMATE CHANGE AND PROJECTS OF ENVIRONMENTAL SERVICES AT INDIGENOUS LANDS OF AMAZON STATE}

\section{ABSTRACT}

Due to the 2005 drought, Amazonas issued the Law no. 3,135/2007, which established the State Policy on Climate Change. The text provided ways of promoting sustainable development, maintaining the climatic conditions and incentives for the participation of the population and the public power in environmental protection. However, about 10 years after its publication, the law seems to have fallen into disuse. Part of the inefficiency is due to the dismantling of the State structure that was acting in the implementation of its instruments and part, due to the lack of complementary regulation. Years later, Amazonas issued Law no. 4,266/2015, which established the State Environmental Services Management System, creating the State Fund for Climate Change and amended Laws nos. 3,135/2007 and 3,184/2007, which alters the Law no. 3,135. The aim of this paper is to evaluate the interaction among all of these norms, through an exercise of interpretation, in order to verify their socio-environmental effectiveness. It was concluded that the participation of traditional communities in conservation units of sustainable use and indigenous peoples on their lands, provides partial effectiveness to Law no. 3,135/2007, by allowing the implementation of projects to reduce emissions from deforestation and degradation in these protected areas, and allowing to pay rewards to environmental service providers.

Keywords: climate changes; indigenous lands; State Law of Amazonas 3, 135/2007; State Law of Amazonas 4,266/2015; Sustainable Use Conservation Units. 


\section{INTRODUÇÃO}

A sociedade amazonense, perplexa após a grande seca de 2005, impulsionou as discussões sobre os efeitos das mudanças no clima sobre o estado. Em resposta a esse revés climático, surge a Lei Estadual n. 3.135/2007, que instituiu a Política Estadual sobre Mudanças Climáticas, Conservação Ambiental e Desenvolvimento Sustentável do Amazonas, ou simplesmente a política estadual sobre mudanças climáticas.

Tal política foi pioneira a respeito do tema no país. Ela previu uma série de instrumentos e mecanismos para promoção do desenvolvimento do estado, buscando sempre reduzir as emissões de gases de efeito estufa. Dessa forma, o Amazonas surge no cenário internacional como exemplo de compromisso com o futuro comum e, ao mesmo tempo, como potencial reserva de carbono a ser protegida e disputada (VIANA, 2008).

Nesse contexto, os mecanismos de desenvolvimento limpo vêm como alternativa viável, a depender, entretanto, de uma ampla articulação política e institucional para promover a regulamentação da lei, conferindo-lhe efetividade plena.

Em 2011, deu-se início as discussões a respeito de uma política estadual de serviços ambientais no Amazonas, concretizada com a Lei estadual n. 4.266/2015, que também instituiu o sistema de gestão de serviços ambientais no estado, criou o Fundo Estadual de Mudanças Climáticas, Conservação Ambiental e Serviços Ambientais, além de alterar as leis estaduais n. 3.135/2007 e 3.184/2007. Esta última, autorizou à época, o estado a participar de uma única fundação privada, com a finalidade de promover programas e projetos de mudanças climáticas, conservação ambiental e desenvolvimento sustentável.

Em 2017, dez anos após a edição da Lei n. 3.135/2007, no entanto, sua regulamentação não veio. Ao contrário, as prioridades políticas mudaram e toda a estrutura institucional de apoio do estado do Amazonas aos instrumentos previstos na lei, integrantes de um sistema transversal distribuído entre a Secretaria de Desenvolvimento Sustentável (SDS) e Secretaria de Estado de Ciência, Tecnologia e Inovação (SECTI), foi desmantelada.

Por outro lado, em um cenário desfavorável, onde atores sociais, políticos e institucionais regionais tendem a acreditar na ineficácia normativa da Lei n. 4.266/2015, surgiu indiretamente uma oportunidade para que os povos indígenas em suas terras pudessem construir, dentro do espírito da norma, projetos de gestão de serviços ambientais para reduzir as emissões de gases decorrentes do desmatamento e da degradação. 
Assim, pretende-se mostrar em um amplo exercício de interpretação do marco regulatório ambiental federal e estadual, possibilidades de um novo caminho para o desenvolvimento regional sustentável, conferindo parcial efetividade a Lei Estadual n. 3.135/2007 (já atualizada pela Lei n. 3.184/2007) por meio da Lei n. 4.266/2015.

Metodologicamente, a pesquisa foi construída sobre escassa base bibliográfica, por se referir, principalmente, a instrumentos legais regionais e pouco estudados. Nesse aspecto, ressalte-se a importância de Roessing Neto (2009), que foi o único estudo específico sobre as leis estaduais em tela. Adicionalmente, realizou-se busca no Portal de Periódicos CAPES (apenas no âmbito de livre acesso), que em setembro de 2019, apresentou os seguintes resultados: i) para a expressão de busca "mudanças climáticas e terras indígenas", obteve-se um total de 36 artigos, todos em periódicos revisados por pares, entre os anos de 2005 até 2018, e; ii) para a expressão de busca "mudanças climáticas e Amazonas", obteve-se um total de 83 artigos, também em periódicos revisados por pares, para os anos de 2005 até 2019. Desse total, apenas dez artigos possuíam alguma relação superficial com o tema aqui abordado.

A exposição segue a sequência iniciada com referida legislação estadual, passando por aspectos institucionais estaduais, a importância das unidades de conservação, terras indígenas e suas populações tradicionais para o desenvolvimento sustentável, buscando, ao final, justificativas legais para eventuais pagamentos pela prestação de serviços ambientais pela implementação de projetos de proteção das florestas em terras indígenas.

\section{O ESTADO DO AMAZONAS E A ORIGEM DA PREOCUPAÇÃO COM AS MUDANÇAS CLIMÁTICAS}

De acordo com o Portal do Governo do Estado do Amazonas (2019), o estado possui cerca de 1,5 milhões de $\mathrm{km}^{2}, 16 \%$ das reservas de água doce da Terra, uma área florestada que compreende $98 \%$ do seu território e grande parte dos estoques de carbono do Brasil. Consoante o IBGE (2010), a população estimada para o estado em 2016 alcançava cerca de 4.001.667 pessoas, apresentando, ainda 168.880 indígenas, de 65 grupos étnicos distintos.

Interessante observar, de acordo com Portal do Governo do Estado do Amazonas (2019), que o principal alicerce econômico do estado é o Polo Industrial de Manaus. Nesse sentido, o próprio Governo do Estado afirma 
que esse modelo de desenvolvimento contribui para minimizar a pressão de desmatamento no Amazonas, devido à substituição de atividades baseadas no uso do solo por uma economia de base industrial.

Apesar do padrão descrito acima, sabe-se que o arco do desmatamento, resultado da expansão da fronteira agrícola, se aproxima do estado, principalmente nos municípios de Boca do Acre e Apuí (YOUNG et al., 2007 apud ROESSING NETO, 2009). Entretanto, de acordo com Bezerra (2012), o desmatamento na Amazônia é instável, o que torna previsões difíceis, apesar de existir forte relação entre degradação ambiental em países com estrutura institucional fraca.

O cenário descrito é preocupante, pois, segundo Fearnside (2004), a floresta amazônica possui importante papel como reguladora do clima no Cone Sul da América do Sul, entendido com a região imediatamente abaixo do Trópico de Capricórnio, sendo responsável por uma parte significativa da chuva no Centro-Sul do Brasil, na Argentina, no Uruguai e no Paraguai. Nesse sentido, impactos à floresta (desmatamento) podem comprometer extensas áreas agrícolas altamente rentáveis. Some-se a este contexto, o fato de que a principal fonte de emissão de Gases de Efeito Estufa (GEE) no Brasil, é exatamente a queima das florestas (SOARES; HIGUCHI, 2006).

Demograficamente, o Amazonas é peculiar. O interior possui baixa densidade e a capital, alta. Em Manaus, de acordo com o IBGE (2010), está concentrada a maior parte da população do estado, que em 2010 era de aproximadamente 1.560 .000 pessoas, distribuídas em uma área de $11.401,092 \mathrm{~km}^{2}$, perfazendo, assim, uma densidade demográfica de 136 $\mathrm{hab} / \mathrm{km}^{2}$.

Assim, em um contexto de abundância de recursos hídricos e florestais e baixa percepção de impactos, qual o motivo que conduziu o Amazonas a se preocupar com a tutela sobre o ambiente a fim de minimizar mudanças climáticas?

De acordo com Serrao et al. (2015), o fator decisivo a incentivar a discussão e posterior produção legislativa sobre mudanças climáticas no estado do Amazonas foi a grande seca de 2005. Naquela época, segundo Serrao et al. (2015), constatou-se uma redução de pluviosidade da ordem de $8,47 \%, 27,86 \%$ e $29,94 \%$, respectivamente, nos meses de maio, junho e julho em relação ao ano anterior, consubstanciando uma seca recorde. Instalou-se a calamidade no interior do estado. A alta mortandade de peixes e os prejuízos à agricultura, associados ao isolamento de muitas comunidades obrigou a realização de uma operação militar conjunta para 
distribuir alimentos e remédios para a população atingida (ROESSING NETO, 2009).

Segundo Roessing Neto (2009), a seca teve relação com o efeito estufa, com o aumento da temperatura no Atlântico e com o aumento das queimadas. Contudo, dentre as causas das alterações climáticas no Amazonas, observa-se não apenas os efeitos do aquecimento global, mas também mudanças socioeconômicas regionais originadas pelo adensamento populacional (conforme Tabela 1, adaptada de IBGE, 2010).

Tabela 1 Crescimento Populacional de Manaus

\begin{tabular}{|c|c|c|}
\hline Censo & População & $\mathbf{\%}$ \\
\hline 1872 & 29334 & $32,0 \%$ \\
\hline 1890 & 38720 & $29,9 \%$ \\
\hline 1900 & 50300 & $50,5 \%$ \\
\hline 1920 & 75704 & $40,5 \%$ \\
\hline 1940 & 106399 & $31,2 \%$ \\
\hline 1950 & 139620 & $25,6 \%$ \\
\hline 1960 & 175343 & $79,2 \%$ \\
\hline 1970 & 314197 & $104,5 \%$ \\
\hline 1980 & 642492 & $57,3 \%$ \\
\hline 1991 & 1010544 & $38,9 \%$ \\
\hline 2000 & 1403796 & $28,4 \%$ \\
\hline 2010 & 1802014 & $49,2 \%$ \\
\hline Est. 2016 & 2094391 & \\
\hline
\end{tabular}

Fonte: Censos demográficos do IBGE de 1872-2010 (IBGE, 2010).

A explosão demográfica de Manaus gerou problemas sociais e econômicos, pois grande parte do excesso populacional se fixou nas periferias da cidade, alargando suas fronteiras, ocupando vales, pântanos, alagados, zonas verdes particulares e áreas de proteção ambiental; em consequência, influindo diretamente no clima pelo aumento na emissão de $\mathrm{CO}_{2}$ por desmatamento.

Tais eventos acabaram por constituir em um marco nas discussões sobre mudanças climáticas no Amazonas, que, em junho de 2007, resultou na Lei Ordinária n. 3.135, que será analisada na sequência.

\section{COMENTÁRIOS À LEI N. 3.135 DE 5 DE JUNHO DE 2007, DO ESTADO DO AMAZONAS}

A Lei Estadual n. 3.135/2007 veio considerar e reconhecer a importância da conservação das florestas como forma de evitar os efeitos nocivos 
da mudança global do clima e promover o desenvolvimento sustentável da economia, do meio ambiente, da tecnologia e da qualidade de vida das presentes e futuras gerações.

Nessa senda, a referida lei toma como balizas norteadoras os seguintes princípios de Direito Ambiental, todos expressos em seu art. $1^{\circ}$, II: prevenção, precaução, responsabilidades comuns, desenvolvimento sustentável, participação e, cooperação nacional e internacional.

Para atribuir efetividade a Política Estadual sobre Mudanças Climáticas, a lei criou instrumentos econômicos, financeiros e fiscais, para a promoção dos seus objetivos, diretrizes, ações e programas.

Dentre os principais instrumentos, há a previsão de fomento e criação de mecanismos de mercado para viabilizar a execução de projetos de redução de emissões do desmatamento (RED), energia limpa (EL), além de emissões líquidas de GEE, dentro ou fora do Protocolo de Quioto (Mecanismo de Desenvolvimento Limpo).

A referida lei considera a importância de se estimular projetos voluntários voltados à utilização do Mecanismo de Desenvolvimento Limpo (MDL) e outros mecanismos e/ou regimes de mercado de créditos de carbono certificados que contribuam efetivamente para a estabilização da concentração de gases de efeito estufa.

Por tal motivo, prevê também uma série de atividades e medidas para viabilizar o desenvolvimento sustentável do estado, partindo de inventários de emissões e biodiversidade. Traz ainda a possibilidade de incentivar (financeiramente) o desenvolvimento e o intercâmbio de inciativas replicáveis na criação de tecnologias que permitam a redução líquida de GEE, projetos de MDL e RED.

Como atividade complementar e não menos importante, a lei menciona a promoção de ações de educação ambiental sobre os impactos e consequências das mudanças climáticas para as comunidades tradicionais, carentes e para os alunos da rede pública escolar, por meio de cursos, publicações impressas e Internet. Tais ações viriam a proporcionar ainda a conscientização da população do Amazonas, sobre o aquecimento global.

Numa outra vertente, a legislação permite e incentiva a elaboração de planos de ação que contribuam para mitigar os efeitos adversos das mudanças climáticas, e a criação de selos de certificação às entidades públicas e privadas que desenvolvam projetos no âmbito das mudanças climáticas, conservação ambiental e desenvolvimento sustentável no Amazonas.

Tal diploma legal criou ainda diferentes projetos que objetivam a 
redução das emissões originárias do desmatamento e das emissões líquidas de gases de efeito estufa, bem como estabeleceu instrumentos de incentivo para viabilizar sua execução. Ao total, foram criados sete programas, conforme disposto no art. $5^{\circ}$ da lei, quais sejam: (I) Programa Estadual de Educação sobre Mudanças Climáticas; (II) Programa Bolsa Floresta; (III) Programa Estadual de Monitoramento Ambiental; (IV) Programa Estadual de Proteção Ambiental; (V) Programa Estadual de Intercâmbio de Tecnologias Limpas e Ambientalmente Responsáveis; (VI) Programa Estadual de Capacitação de Organismos Públicos e Instituições Privadas; e (VII) Programa Estadual de Incentivo à Utilização de Energias Alternativas Limpas e Redutoras da Emissão de Gases de Efeito Estufa.

Por fim, a lei prevê a implementação de projetos de pesquisa em Unidades de Conservação (UC's), utilizando-se basicamente do sistema de Ciência, Tecnologia e Inovação do estado, especialmente por meio da Fundação de Amparo à Pesquisa do Estado do Amazonas (FAPEAM), além da criação de novas Unidades de Conservação e a instituição, no âmbito do Zoneamento Econômico Ecológico, de indicadores ou zonas que apresentem áreas de maior vulnerabilidade às mudanças climáticas.

Interessante observar que a política em questão, apesar de estadual, apresenta impactos internacionais, ao situar o Amazonas como espaço territorial especialmente tutelado com vistas a redução das emissões de GEE em um âmbito maior. Dessa forma, ela apresenta necessária interface com o Tratado de Cooperação Amazônica (TCA), instituído em 1978 pelas partes (Brasil, Bolívia, Colômbia, Equador, Guyana, Peru, Suriname e Venezuela) como diretriz de desenvolvimento sustentável de toda a bacia (BRASIL, 2017).

A lei amazonense considera também a Convenção-Quadro das Nações Unidas sobre Mudança do Clima, o Protocolo de Quioto, além de decisões editadas em consonância com a Política Estadual sobre Mudanças Climáticas, Conservação Ambiental e Desenvolvimento Sustentável do Estado. Ressalta ainda os impactos sociais, econômicos e ambientais das mudanças climáticas e os seus efeitos esperados, em especial para a Floresta Amazônica, além da decisão do Governo do Estado do Amazonas em contribuir voluntariamente para a estabilização da concentração de gases de efeito estufa nos setores florestal, energético, industrial, de transporte, saneamento básico, construção, mineração, pesqueiro, agrícola ou agroindustrial.

A Lei estadual n. 3.135/2007 trata-se (ainda hoje) de legislação inovadora, não apenas por servir de modelo ao Brasil (que apenas em 2009 
publicou sua Política Nacional sobre Mudanças no Clima, Lei n. 12.187, de 29 de dezembro de 2009), mas por incentivar as empresas a reduzirem emissões de gases poluentes, penalizando aquelas que descumprirem a referida legislação. No entanto, vislumbra-se não apenas o caráter repressivo, mas principalmente o preventivo, por ter como objeto a conservação da maior floresta tropical do mundo, proporcionando meios para manter o equilíbrio dos ecossistemas regionais frente às mudanças climáticas decorrentes do aquecimento global.

\section{COMENTÁRIOS À LEI N. 4.266 DE 01 DE DEZEMBRO DE 2015, DO ESTADO DO AMAZONAS}

A Lei Estadual n. 4.266/2015, institui a Política do Estado do Amazonas de Serviços Ambientais e o Sistema de Gestão dos Serviços Ambientais, cria o Fundo Estadual de Mudanças Climáticas, Conservação Ambiental e Serviços Ambientais, altera as Leis Estaduais n. 3.135/2007 e 3.184/2007, e dá outras providências.

Em seu art. $2^{\circ}$, é apresentado uma série de definições de interesse da matéria, com destaque para os incs. II e XXVIII, a, b, c, d, nos seguintes termos:

II - agentes de serviços ambientais: todas as pessoas físicas ou jurídicas que contribuam, desenvolvam, promovam, utilizem, regulem, executem e invistam em atividades que beneficiam a manutenção, a integridade ou melhoram e recuperam funções e processos geradores dos serviços ambientais;

$[\ldots]$

XXVIII - serviços ambientais ou ecossistêmicos: processos e funções ecológicas relevantes gerados pelos ecossistemas, em termos de manutenção, recuperação ou melhoramento das condições ambientais, em benefício do bem-estar de todas as sociedades humanas e do planeta, nas seguintes modalidades:

a) serviços de provisão: são relacionados com a capacidade dos ecossistemas em prover bens, sejam eles alimentos (frutos, raízes, pescado, caça, mel); matéria-prima para a geração de energia (lenha, carvão, resíduos, óleos); fibras (madeira, cordas, têxteis); fitofármacos; recursos genéticos e bioquímicos; plantas ornamentais e água; b) serviços de suporte: são os processos naturais necessários para a existência dos outros serviços, como a ciclagem de nutrientes, a decomposição de resíduos, a produção primária, a manutenção ou a renovação da fertilidade do solo, a polinização, a dispersão de sementes, o controle de populações de potenciais pragas e de vetores potenciais de doenças humanas, a proteção contra a radiação solar ultravioleta, a manutenção da biodiversidade e do patrimônio genético, entre outros que mantenham a perenidade da vida na Terra; 
c) serviços de regulação: são os benefícios obtidos a partir de processos naturais que regulam as condições ambientais que sustentam a vida humana, como a purificação do ar, regulação do clima, purificação e regulação dos ciclos das águas, controle de enchentes e de erosão; tratamento de resíduos, desintoxicação e controle de pragas e doenças;

d) serviços culturais: os que proveem benefícios imateriais, educacionais, recreacionais, estéticos e espirituais; (grifos nossos)

Observa-se que o inc. II apresenta o agente de serviços ambientais como a pessoa física ou jurídica que melhora e/ou recupera os processos geradores dos serviços ambientais, enquanto o inc. XXVIII coloca serviços ambientais como sinônimo de ecossistêmicos. Esta aparente redundância demonstra a imprecisão terminológica do texto legal, uma vez que não traz a diferenciação fundamental entre serviços ecossistêmicos e serviços ambientais.

A despeito de ainda não haver consenso doutrinário sobre a questão, faz-se mister a diferenciação entre os termos, para a própria viabilidade da prestação dos serviços ambientais. Assim, tem-se dois objetos distintos: os serviços ambientais, enquanto uma ação humana voluntária em prol dos serviços ecossistêmicos, que são os processos ecológicos, sistêmicos e seus reflexos em benefício do próprio homem. Nesse sentido, observa-se a reflexão de Camargo (2015, p. 05):

Serviços ambientais e serviços ecossistêmicos são termos que designam objetos teóricos distintos, uma vez que estes são os serviços prestados gratuitamente pelo ambiente em prol da sociedade, enquanto os serviços ambientais são prestados pelo homem, em benefício dos ecossistemas. Assim, tem-se que qualquer pessoa física ou jurídica que proteger, manter, preservar, conservar ou manejar diretamente um bem natural ou um ecossistema, que é provedor de serviços ecossistêmicos, é prestadora de um serviço ambiental.

Sob esse enfoque, considerando os serviços ambientais como uma efetiva prestação de serviços por uma pessoa física ou jurídica, tem-se que melhorar e/ou recuperar por ação humana um processo gerador de uma função ecológica qualquer, difere profundamente do serviço ecossistêmico beneficiado, que, a priori, não guarda relação direta com a ação voluntária do agente (seja pessoa física ou jurídica).

Camargo (2015 p. 05) ainda esclarece que o princípio do protetor-recebedor é o fundamento jurídico para respaldar a recompensa aos agentes provedores de serviços ambientais, in verbis: 
Com base no princípio do protetor-recebedor, esse prestador poderá ser recompensado pelo serviço ambiental em si, não pelos serviços ecossistêmicos dele decorrentes. Essa recompensa pode se dar através de diferentes instrumentos econômicos, como incentivos ou pagamentos, em sistemas de compensação de serviços ambientais, sendo os beneficiários incentivadores/pagadores definidor por lei ou contrato. Tais sistemas, no entanto, não se confundem com os conhecidos esquemas de pagamento por serviços ambientais - PSA, pois aqueles são o gênero do qual o PSA é apenas uma subespécie, que só se configura quando há adicionalidade e voluntariedade na prestação do serviço ambiental. Dessa forma, vários sistemas de compensação existentes que são denominados de pagamento por serviços ambientais, na verdade, correspondem a outras modalidades de compensação, que não é pagamento, ou compensam/retribuem atividades que não podem ser tidas como serviços ambientais. É o que acontece, especificamente, com os três casos da Amazônia brasileira analisados: o programa Bolsa Verde do governo federal, o Bolsa Floresta do Estado do Amazonas e o PSA da pesca esportiva de Barcelos-AM. Essa impropriedade conceitual gera importantes consequências práticas, como a possibilidade de acesso a recursos de fundos voltados à proteção ambiental por programas que, em geral, são meras políticas de transferência de renda. Dessa forma, verifica-se que a grande problemática não é legal, mas sim de conceito, pois a legislação posta já é capaz de regulamentar o tema.

Nesta perspectiva, Camargo (2015) ainda apresenta os diferentes tipos de serviços ambientais, sendo a classificação quanto à natureza da prestação do serviço ambiental a que possui relevância para o presente trabalho. Segundo a autora, os serviços ambientais podem ser caracterizar pelo (I) aumento de externalidade positivas ou (II) pela redução de externalidades negativas por meio de mitigação ou substituição.

O aumento de externalidades positivas se daria pelos serviços de proteção (conservação ou manutenção) e de recuperação, como por exemplo a criação de unidades de conservação (serviço de proteção) e a recuperação de áreas de preservação permanente ou de reserva legal degradadas (recuperação). Por outro lado, a substituição seria o uso de sistemas artificiais ou seminaturais para a execução de funções equivalentes a dos serviços ecossistêmicos, como a despoluição da água de um rio. Já a mitigação seria o serviço ambiental que leva a mudanças na prática de manejo de ecossistemas ou recursos, reduzindo, então, o impacto sobre os ecossistemas ou a sua demanda pelos serviços ecossistêmicos.

Adotando a classificação de serviços ambientais proposta por $\mathrm{Ca}$ margo (2015), verifica-se que a redução de emissões por desmatamento e degradação florestal (REDD) seria um serviço ambiental de redução de externalidades negativas por meio de mitigação ou substituição. 
Resta ainda uma importante consideração sobre os serviços ambientais e seus respectivos pagamentos ou recompensas. Esses serviços devem ser voluntários, caracterizando um plus, ou uma adicionalidade, indo além das obrigações mínimas estabelecidas em lei. Voluntários, pois não se pode recompensar alguém por simplesmente cumprir a lei, por exemplo: o Código Florestal (Lei n. 12.651/2012) estabelece a obrigatoriedade da manutenção de áreas de reserva legal e das áreas de preservação permanente; o proprietário rural que simplesmente cumprir com as determinações legais, não faria jus ao recebimento de recompensa pelo desmatamento evitado em sua propriedade (BRASIL, 2012a). Por outro lado, se a lei estabelece um percentual mínimo de cobertura vegetal a ser mantido naquele bioma e, voluntariamente, o proprietário rural preserva área superior, caracterizando um plus à determinação legal, faria então jus ao recebimento de um pagamento por serviço ambiental prestado, pois ao extrapolar o mínimo legal, adicionou maior eficiência na manutenção de serviços ecossistêmicos.

\section{ASPECTOS INSTITUCIONAIS E ENTRAVES LEGAIS}

No intuito de operacionalizar os ditames legais mencionados acima, conferindo maior efetividade à lei, o estado do Amazonas contava com uma estrutura administrativa bastante peculiar e positiva. À época da edição da lei, em 2007, existiam duas Secretarias de Estado e alguns órgãos internos que cuidavam diretamente do fomento à pesquisa, desenvolvimento de tecnologia e inovação, além de centros para tratar da criação e gestão de UC's estaduais e políticas públicas voltadas à redução da emissão de GEE e demais atividades relacionadas a minimização dos efeitos das mudanças climáticas. Em relação ao fomento, existia a Secretaria de Estado de Ciência, Tecnologia e Inovação (SECTI) e, vinculada a ela, a Fundação de Amparo à Pesquisa do Estado do Amazonas (FAPEAM), como agência financiadora em um modelo precipuamente de demanda induzida. Em outra frente, observava-se a Secretaria Estadual de Meio Ambiente e Desenvolvimento Sustentável (SDS), o Centro Estadual de Unidades de Conservação (CEUC) e o Centro Estadual de Mudanças Climáticas (CECLIMA).

Em março de 2015, o Governador do Estado, surpreendentemente, tomou uma série de medidas que impactaram de forma profunda o sistema até então existente, ao definir uma reforma administrativa, descrita pelo Greenpeace Brasil (2015) como desastrosa. Ressalta o Greenpeace que a reforma extinguiu a Secretaria de Estado de Ciência, Tecnologia e 
Inovação, considerada estratégica; além do Centro Estadual de Unidades de Conservação, responsável pela gestão de 42 áreas estaduais de proteção ambiental, e o Centro Estadual de Mudanças Climáticas. As mudanças administrativas resultaram tembém na redução do orçamento e do quadro de servidores da Secretaria Estadual de Meio Ambiente e Desenvolvimento Sustentável, comprometendo gravemente o combate ao desmatamento.

Conforme observa o Greenpeace Brasil (2015), o Governo do Estado do Amazonas rompeu com a postura tradicional de tutela do meio ambiente, por meio de arrojada política de criação e gestão de UC's estaduais, que além de servirem à propósitos sociais e econômicos por meio da regularização fundiária, formavam grande reservatório de carbono, contribuindo para redução da pressão por desmatamento e ainda, possibilitando a implementação de projetos de RED por parte de populações tradicionais.

Constata-se, nesse sentido, uma oportunidade que referida legislação abriu para as populações tradicionais e que ainda permanece pouco debatida pela literatura. Apesar de conferir ampla efetividade a lei, a implementação de projetos de RED foge aos mecanismos de comando e controle do estado, colocando as populações tradicionais no centro de um protagonismo com viés socioambiental. Santos (2013) menciona que no Acre e no Amazonas houve um grande movimento para a criação de unidades de conservação de uso sustentável, com o objetivo principal de conter o desmatamento. Nesse aspecto, o referido autor indica que os seringueiros do Acre exerceram importante protagonismo na luta pela terra, enquanto no Amazonas, os ribeirinhos lutavam pela preservação de lagos de várzea e dos recursos pesqueiros.

Nesse contexto, observa-se que das unidades de conservação criadas no Amazonas, perfazendo 18.808.342,60 ha, 81,41\% pertencem à categoria de uso sustentável, principalmente no formato de Reservas de Desenvolvimento Sustentável (SANTOS, 2013).

Pelo exposto, verifica-se que a demanda por terra relaciona-se estreitamente ao exercício do protagonismo dessas populações tradicionais, ora beneficiadas pela criação de diversas UC's de uso sustentável. Conforme o Sistema Nacional de Unidades de Conservação - SNUC (Lei n. 9.985 de 18 de julho de 2000), uma das funções precípuas das UC's de uso sustentável é exatamente garantir a forma de vida tradicional dessas populações, normalmente caracterizada pela sustentabilidade, alta dependência de recursos naturais, uso de tecnologias rudimentares e baixa escala de aproveitamento (DIEGUES, 1999). Sendo assim, naturalmente a pressão 
por desmatamento nessas áreas é menor, mantendo-se a higidez ambiental e favorecendo o equilíbrio dos serviços ecossistêmicos. Nesse sentido, discorre Becker (2010) que em tempos recentes, as funções dos ecossistemas passaram a ser valoradas economicamente por meio dos serviços ambientais; permitindo a criação de mecanismos para redução das emissões por desmatamento e degradação, que passariam pelo desenvolvimento de uma estratégia nacional desses mecanismos, pela implementação de políticas nacionais para comercialização de créditos de carbono, até atingir a fase do pagamento pelas efetivas reduções nas emissões.

Assim, apesar de se observar entraves institucionais que comprometem a eficácia da norma, a legislação em tela deixou a oportunidade para que populações tradicionais indígenas e não indígenas contribuíssem voluntariamente com a redução das emissões de GEE por meio de projetos de REDD em unidades de conservação de uso sustentável e terras indígenas.

As unidades de conservação da natureza possuem, entretanto, regime jurídico diferenciado. O Sistema Nacional de Unidades de Conservação da Natureza, instituído pela Lei n. 9.985/2000 prevê duas categorias de unidades de conservação: uso sustentável e proteção integral. As unidades de proteção integral por sua própria destinação e permissão apenas de uso indireto de recursos naturais, não ensejaria o pagamento/recebimento de recompensas pela redução da pressão por desmatamento, justamente por não se caracterizar a voluntariedade ou plus na prestação de um serviço, ainda que realizado por pessoa jurídica na gestão daquela unidade.

Observe-se que neste aspecto, não há voluntariedade nem mesmo no ato de criação de unidades de conservação, pois conforme disposto no art. 225, § $1^{\text {o }}$, I, II, III, VIII, da Constituição Federal, é dever do Poder Público proteger o ecossistema e seus processos, além da biodiversidade e patrimônio genético, devendo para tanto, instituir áreas protegidas (UC's), podendo para tal finalidade se utilizar de terras devolutas. Assim, partindo-se do pressuposto que o referido art. 225 encerra um direito fundamental, não há margem para discricionariedade do Estado, que deve proteger o meio ambiente ecologicamente equilibrado para as presentes e futuras gerações.

Ressalte-se que as unidades de proteção integral, previstas no art. $7^{\circ}$, $\S 1^{\circ}$, da Lei n. 9.985/2000, destinam-se a "preservar a natureza, sendo admitido apenas o uso indireto dos seus recursos naturais, com exceção dos casos previstos nesta Lei". Tais exceções são medidas que visam a regeneração dos ecossistemas impactados de alguma forma. Nesse sentido, também não haveria voluntariedade, pois o gestor da unidade de conservação, 
normalmente de domínio público, estaria adstrito ao mero cumprimento da lei.

A oportunidade nessa categoria espacial, reside nas unidades de uso direto e sustentável, principalmente (mas não exclusivamente) em reservas extrativistas (RESEX) e reservas de desenvolvimento sustentável (RDS), ambas previstas no art. 14 da Lei n. 9.985/2000.

A RESEX, conforme dispõe o art. 18 da referida lei, permite a exploração/manejo sustentável de recursos naturais por populações tradicionais, com base em um plano de manejo. Observa-se ainda, no $\S 7^{\circ}$ do mesmo artigo, que o manejo florestal só será admitido em bases sustentáveis, devendo ser complementar às demais atividades desenvolvidas na RESEX. De toda sorte, conforme mencionado, todas as atividades desenvolvidas no interior da unidade estão sujeitas ao plano de manejo, a ser elaborado com a participação das comunidades tradicionais, que após sua aprovação pelo conselho deliberativo, vincula os moradores da área. Nesse aspecto, tem-se novamente uma certa dubiedade na caracterização da voluntariedade de eventual serviço ambiental prestado por residentes. Tal situação somente se caracterizaria em situação onde apesar de permitido o manejo, este não fosse voluntariamente realizado, ensejando resultados positivos e adicionais na conservação do meio, com reflexos diretamente observados na manutenção e incremento de serviços ecossistêmicos. Nestes casos, portanto, tais serviços deveriam ser medidos e recompensados proporcionalmente.

A situação das RDS's não difere. A peculiaridade maior neste tipo de unidade relaciona-se à desnecessidade precípua de desapropriação de todas as áreas abrangidas no ato de criação. A RDS é compatível com a propriedade privada, desde que as atividades desenvolvidas pelos proprietários de terras em seu interior sejam compatíveis com o plano de manejo. Novamente, tem-se a necessidade de uma ponderação sobre a voluntariedade e adicionalidade dos serviços ambientais ali prestados, a fim de que resultem em direito de recompensa.

Importante observar nesse sentido, que a lei amazonense, ao incentivar mecanismos de redução de emissões por desmatamento e degradação, abriu uma interessante oportunidade para integração do sistema estadual de unidades de conservação ao mercado de créditos de carbono.

Entretanto, conforme ressaltado acima, a articulação entre a gestão de UC's no estado do Amazonas e a efetiva implementação de projetos de redução de emissão por desmatamento e degradação, depende de um sistema institucional (estadual) atuante, com a participação de comunidades tradicionais. Dessa forma, ainda que existente um sistema estadual, 
como de fato se observa, o desmantelamento dos órgãos púbicos (CEUC e CECLIMA) e o contingenciamento e/ou redução orçamentária imposta à SDS, além das restrições de recursos humanos, pode conduzir à inefetividade socioambiental da legislação em tela.

Por outro lado, resta uma importante alternativa de oportunidade extra-sistema para se conferir efetividade à norma, as terras indígenas, conforme se verá no item abaixo.

\section{REDD E TERRAS INDÍGENAS}

De acordo com Benjamin (2000), a Lei n. 9985/2000 define duas famílias de Unidades de Conservação: as de proteção integral e as de uso sustentável. Para o Autor, a legislação é exemplificativa, permitindo a inclusão de outros tipos de áreas protegidas no sistema, a exemplo das terras indígenas, e da reserva da biosfera.

A posição acima é bastante interessante, na medida em que aproxima terras indígenas de unidades de uso sustentável, permitindo, assim, uma certa similaridade de intenções, que ensejariam algumas limitações ao usufruto dos indígenas sobre suas terras.

As referidas limitações deveriam conduzir a gestão ambiental em terras indígenas à sustentabilidade, buscando-se compatibilizar o etnodesenvolvimento, preconizado pela própria Convenção n. 169 da Organização Internacional do Trabalho (OIT), com a efetivação do direito fundamental ao meio ambiente ecologicamente equilibrado.

Nessa esteira, o desenvolvimento de projetos de REDD em terras indígenas surge como alternativa viável. Observe-se que, conforme Santilli (2010), o Brasil possui 110 milhões de hectares de terras indígenas, o que corresponde a $13 \%$ do território nacional. Segundo a mesma fonte, 98\% dessas terras encontram-se na Amazônia Legal Brasileira, representando $22 \%$ da extensão territorial da região. As demais áreas protegidas, integrantes do SNUC, também situadas na Amazônia Legal, agregam uma área total de aproximadamente, 13 milhões de hectares, ou 15\% da região, sendo que 3\% da extensão do sistema estão sobrepostos a 7\% das terras indígenas. Por fim, o referido autor ressalta que o desmatamento em terras indígenas na Amazônia é baixo, atingindo cerca de $2 \%$ da extensão total em decorrência das roças, aldeamentos e áreas anteriormente degradadas por posses não indígenas.

Corroborando a informação acima, Dourado et al. (2016) discorrem que entre 2004 e 2006, a expansão das terras indígenas e unidades de 
conservação na Amazônia foi de aproximadamente 24 milhões de hectares, promovendo uma redução no desmatamento na ordem de $37 \%$, permitindo-se inferir que as terras indígenas são importantes para assegurar ações de mitigação de mudanças climáticas, principalmente ao nível regional.

Nesse sentido, Santilli (2010) ensina que o maior objetivo do desenvolvimento de projetos de REDD em terras indígenas é evitar que o padrão de desmatamento observado fora dessas áreas se repita em seu interior. Vale relembrar, contudo, o próprio modelo de desenvolvimento do Amazonas contribui para o sucesso de eventuais projetos, pois o Polo Industrial de Manaus continua exercendo importante papel como atrator populacional e econômico para a capital, protegendo indiretamente o interior do estado (BECKER, 2010).

A grande concentração de terras indígenas na Amazônia pode ainda, segundo Santilli (2010) servir como uma barreira ao arco do desmatamento (entre o leste do Pará, norte do Mato Grosso e centro de Rondônia). Tais áreas deveriam ser priorizadas para implementação de projetos de REDD, por se encontrarem na região de maior pressão por desmatamento do Norte do Brasil.

O quadro 1 abaixo, reproduzido de Santilli (2010), relaciona dados sobre os estoques aproximados de carbono existentes em doze terras indígenas na Amazônia.

Quadro 1 Carbono de Biomassa Aérea em Terras Indígenas na Amazônia Legal Brasileira

\begin{tabular}{|l|c|c|c|c|c|c|}
\hline \multirow{2}{*}{ Terra Indígena } & \multicolumn{2}{|c|}{ Área (ha) } & \multicolumn{2}{c|}{ tC/ha } & \multicolumn{2}{c|}{ Carbono total (t) } \\
\cline { 2 - 7 } & $\begin{array}{c}\text { Carneiro, } \\
\text { A. } \\
2009\end{array}$ & $\begin{array}{c}\text { Saatchi et al. } \\
2009\end{array}$ & $\begin{array}{c}\text { Carneiro, } \\
\text { A. } \\
2009\end{array}$ & $\begin{array}{c}\text { Saatchi } \\
\text { et al. } \\
2009\end{array}$ & $\begin{array}{c}\text { Carneiro, A. } \\
2009\end{array}$ & $\begin{array}{c}\text { Saatchi et al. } \\
2009\end{array}$ \\
\hline Yanomami & 9.589 .302 & 9.523 .037 & 149 & 111 & 1.432 .598 .612 & 1.057 .057 .107 \\
\hline Vale do Javari & 8.561 .824 & 8.515 .001 & 148 & 131 & 1.264 .825 .726 & 1.115 .596 .131 \\
\hline Alto Rio Negro & 8.034 .176 & 7.979 .953 & 150 & 125 & 1.201 .268 .666 & 997.494 .125 \\
\hline Menkragnoti & 4.928 .083 & 4.907 .539 & 141 & 81 & 694.721 .947 & 397.510 .659 \\
\hline Trombetas/Mapuera & 4.002 .902 & 3.984 .974 & 155 & 134 & 619.695 .304 & 533.986 .516 \\
\hline Kayapó & 3.307 .878 & 3.293 .920 & 123 & 84 & 407.685 .159 & 276.689 .280 \\
\hline Waimiri-Atroari & 2.602 .964 & 2.591 .312 & 151 & 149 & 392.191 .734 & 386.105 .488 \\
\hline Tumucumaque & 3.069 .940 & 3.053 .109 & 126 & 117 & 386.346 .228 & 357.213 .753 \\
\hline Mundurucu & 2.397 .454 & 2.387 .301 & 107 & 107 & 256.179 .665 & 255.441 .207 \\
\hline Xingu & 2.646 .405 & 2.636 .116 & 89 & 69 & 234.674 .949 & 181.892 .004 \\
\hline Alto Rio Guamá & 280.416 & 279.164 & 153 & 120 & 42.788 .995 & 33.499 .680 \\
\hline Sete de Setembro & 244.196 & 243.225 & 149 & 106 & 36.285 .040 & 25.781 .850 \\
\hline
\end{tabular}

Fonte: Santilli (2010, p. 15). 
Importante mencionar que, de acordo com Santilli (2010), se os indígenas, hipoteticamente, decidissem suprimir $20 \%$ das florestas de suas terras, algo possível ao se inserir os limites do usufruto sobre suas terras no contexto do novo Código Florestal (Lei n. 12.651/2012), isto acarretaria emissões futuras da ordem de $2,8 \mathrm{GtC}$, perfazendo $460 \%$ do volume total de emissões que o Brasil pretende reduzir até 2020.

Isto indica claramente a importância não apenas da manutenção e gestão ambiental corretas dessas áreas, mas a implementação de projetos de prestação de serviços ambientais por REDD como forma de reduzir a pressão por desmatamento, proporcionando alternativas econômicas viáveis aos indígenas, que poderiam optar por ações voluntárias de manutenção de áreas protegidas maiores que os limites estabelecidos na legislação ambiental. Neste caso fariam jus à recompensas proporcionais por serviços ambientais prestados, além das divisas provenientes da comercialização de créditos de carbono.

\subsection{Terras Indígenas e Gestão Ambiental}

De maneira sucinta, convém salientar ainda que a eventual implementação de projetos de serviços ambientais por REDD em terras indígenas viria ao encontro dos objetivos preconizados pelo Decreto n. 7.747 de 05 de junho de 2012, que institui a Política Nacional de Gestão Territorial e Ambiental de Terras Indígenas (PNGATI) (BRASIL, 2012b).

O referido decreto, na esteira da Convenção n. 169 da Organização Internacional do Trabalho (OIT), vem reafirmar o protagonismo dos povos indígenas e seu empoderamento em vista do etnodesenvolvimento pautado na autodeterminação. Tais diplomas também reafirmam a autonomia dos povos indígenas, no exercício cotidiano do usufruto sobre suas terras, impondo entretanto alguns limites.

Conforme mencionado acima, terras indígenas podem ser consideradas unidades de conservação de uso sustentável extra-sistema (BENJAMIN, 2000). Assim, o plano de gestão ambiental dessas terras poderia prever instrumentos de proteção ambiental, que ao mesmo tempo permitissem a prática de mecanismos de desenvolvimento limpo, a exemplo dos projetos de REDD.

Apesar de o Decreto n. 7.747/2012 prever a realização de etnomapeamento e etnozoneamento como substratos do plano de gestão ambiental, ou seja, apesar de garantir a participação das comunidades 
indígenas na elaboração desses planos (BRASIL, 2012b), de acordo com Oliveira e Tsamaren (2017), há diferentes meandros internos (culturalmente e institucionalmente estabelecidos), até uma efetiva tomada de decisão. Importante também ressaltar que os indígenas possuem uma temporalidade própria, que pode acabar por conferir inefetividade prática aos dispositivos legais, quando premidos pelo aproveitamento econômico de suas terras aos moldes tradicionais (a exemplo da agricultura e da pecuária). $\mathrm{O}$ imediatismo não poupa as populações tradicionais, também influenciadas por expectativas de ganho em curto prazo.

Cabe nesse sentido, um pequeno alerta: propostas de implementação de projetos de REDD devem ser levadas até os povos indígenas, provocando as instâncias internas de tomada de decisão a apreciá-las de forma participativa, aos moldes da consulta prévia instituída na Convenção n. 169 da OIT.

\section{CONCLUSÃO}

O resgate da efetividade da norma, neste caso, se deu por vias indiretas. A legislação amazonense, conforme se observou, ao adotar os princípios da precaução e da prevenção já abre inúmeras possibilidades para implementação de projetos de proteção ambiental, sejam ou não em terras indígenas.

A vantagem que existe em relação às terras indígenas, em um contexto de redução do desmatamento e das emissões de gases de efeito estufa, advém da integridade biótica dos sistemas, das grandes áreas protegidas, dos grandes estoques de carbono disponíveis, da localização estratégica para conter o arco do desmatamento e, principalmente, pela possibilidade de se empoderar os povos indígenas para que adotem um modelo sustentável de usufruto, rumo a um etnodesenvolvimento protagonizado pelos próprios povos autóctones, a teor da Convenção n. 169 da OIT. Seria uma forma de compatibilizar os compromissos de redução de emissão assumidos pelo Brasil perante a comunidade internacional e, ao mesmo tempo, respeitar o direito à diferença, constitucionalmente garantido aos indígenas.

Conforme se observou, há uma grande semelhança entre terras indígenas e unidades de conservação de uso sustentável. Em ambos os casos, eventuais benefícios da prestação de serviços ambientais por povos tradicionais (indígenas e não indígenas), assim como da implementação de projetos de REDD, deveriam obrigatoriamente reverter para essas populações, 
vez que o Estado não demarca terras indígenas e nem mesmo cria unidades de conservação voluntariamente, mas o faz por determinação constitucional. Não é possível recompensar o Estado por cumprir normas constitucionais, ao dar efetividade ao direito fundamental ao meio ambiente ecologicamente equilibrado. Tais recompensas poderiam ainda ferir o princípio do acesso equitativo aos recursos naturais, possibilitando ao Estado uma espécie de enriquecimento ilícito, ao substituir/excluir os verdadeiros beneficiários da prestação de serviços ambientais.

Assim, cabe aos povos tradicionais ir além, implementando medidas voluntárias mais restritivas e benéficas ao meio ambiente (prestação de serviços ambientais), do que a própria lei determina ao definir áreas de reserva legal, áreas de preservação permanente, planos de manejo e mesmo planos de gestão ambiental e territorial.

As possibilidades existem e não carecem de regulamentação adicional ao marco legal já existente e analisado acima. Conclui-se, então, que os meios de vida sustentáveis praticados pelos indígenas e demais comunidades tradicionais em seus territórios, serviriam como prestação de serviços ambientais e, consequentemente, forma de resgate parcial da efetividade da lei amazonense, dez anos após sua edição.

\section{REFERÊNCIAS}

AMAZONAS. Governo do Estado. O Amazonas: dados. Disponível em: http:/www.amazonas.am.gov.br/o-amazonas/dados/. Acesso em: 5 out. 2019.

AMAZONAS (Estado). Lei n. 3.135, de 5 de junho de 2007. Institui a política estadual sobre mudanças climáticas, conservação ambiental e desenvolvimento sustentável do Amazonas, e estabelece outras providências. Disponível em: http://online.sefaz.am.gov.br/silt/Normas/Legisla\%E7\%E3o\%20Estadual/Lei\%20Estadual/Ano\%202007/Arquivo/ LE\%203135\%2007.htm. Acesso em: 4 out. 2019.

AMAZONAS (Estado). Lei n. 4.266 de 01 de dezembro de 2015. Institui a Política do Estado do Amazonas de Serviços Ambientais e o Sistema de Gestão dos Serviços Ambientais, cria o Fundo Estadual de Mudanças Climáticas, Conservação Ambiental e Serviços Ambientais, altera as Leis Estaduais n. 3.135/2007 e 3.184/2007, e dá outras providências. Disponível em: http://online.sefaz.am.gov.br/silt/Normas/Legisla $\%$ E7\%E3o\%20 
Estadual/Lei\%20Estadual/Ano\%202015/Arquivo/LE\%204.266_15.htm. Acesso em: 4 out. 2019.

AMAZONAS (Estado). Lei n. 3.184, de 13 de novembro de 2007. Altera, na forma que especifica, a Lei n. 3.135, de 05 de junho de 2007, e dá outras providências. Disponível em: http:/online.sefaz.am.gov.br/silt/Normas/ Legisla\%E7\%E3o\%20Estadual/Lei\%20Estadual/Ano\%202007/Arquivo/ LE\%203184\%2007.htm. Acesso em: 4 out. 2019.

BECKER, B. K. Ciência, tecnologia e inovação: condição do desenvolvimento sustentável da Amazônia. Parcerias Estratégicas, Brasília, DF, v. 15, n. 31, p. 15-33, jul./dez. 2010. Disponível em: http://www1.cgee. org.br/hotsites/cd_berthabecker/pdf/2010-4cncti.pdf. Acesso em: 17 mar. 2017.

BENJAMIN, A. H. V. Uma primeira leitura da nova Lei do Sistema Nacional de Unidades de Conservação. Revista da Associação Paulista do Ministério Público, São Paulo, ano 4, n. 34, ago./set., 2000. Disponível em: http://bdjur.stj.jus.br/jspui/bitstream/2011/27906/Regime_Brasileiro_Unidades.doc.pdf. Acesso em: 23 mar. 2017.

BEZERRA, J. A Amazônia na Rio + 20: as discussões sobre florestas na esfera internacional e o seu papel na Rio + 20. Cad. EBAPE.BR, Rio de Janeiro, v. 10, n. 3, p. 533-545, set. 2012. Disponível em: http://www.scielo. br/pdf/cebape/v10n3/05.pdf. Acesso em: 26 mar. 2020.

BRASIL. Lei n. 9.985, de 18 de julho de 2000. Regulamenta o art. 225, § $1^{\circ}$, incisos I, II, III e VII da Constituição Federal, institui o Sistema Nacional de Unidades de Conservação da Natureza e dá outras providências. Disponível em: http://www.planalto.gov.br/ccivil_03/LEIS/L9985.htm. Acesso em: 5 out. 2019.

BRASIL. Lei $n$. 12.187, de 29 de dezembro de 2009. Institui a Política Nacional sobre Mudança do Clima - PNMC e dá outras providências. Disponível em: http://www.planalto.gov.br/ccivil_03/_ato2007-2010/2009/lei/ 112187.htm. Acesso em: 5 out. 2019.

BRASIL. Lei n. 12.651, de 25 de maio de 2012a. Dispõe sobre a proteção da vegetação nativa; altera as Leis n.s 6.938, de 31 de agosto de 1981, 9.393, de 19 de dezembro de 1996, e 11.428, de 22 de dezembro de 2006; revoga as Leis n.s 4.771, de 15 de setembro de 1965, e 7.754, de 14 de abril de 1989, e a Medida Provisória n. 2.166-67, de 24 de agosto de 2001; 
e dá outras providências. Disponível em: http://www.planalto.gov.br/ccivil_03/_Ato2011-2014/2012/Lei/L12651.htm. Acesso em: 5 out. 2019.

BRASIL. Decreto n. 7.747 de 5 de junho de 2012b. Institui a Política Nacional de Gestão Territorial e Ambiental de Terras Indígenas - PNGATI, e dá outras providências. Disponível em: http://www.planalto.gov.br/ccivil_03/_ato2011-2014/2012/decreto/d7747.htm. Acesso em: 07 out. 2019.

BRASIL. Ministério das Relações Exteriores. Organização do Tratado de Cooperação Amazônica (OTCA), 2017. Disponível em: http://www.itamaraty.gov.br/pt-BR/politica-externa/integracao-regional/691-organizacao-do-tratado-de-cooperacao-amazonica-otca. Acesso em: 6 abr. 2017.

CAMARGO, T. R. L. Tutela jurídica dos sistemas de compensação de serviços ambientais. Manaus: UFAM, 2015.

DIEGUES, A. C. Biodiversidade e comunidades tradicionais no Brasil. São Paulo: NUPAUB/USP, PROBIO/MMA, CNPq, 1999.

DOURADO, M. F. et al. A gestão ambiental e territorial de terras indígenas: uma questão climática. Brasiliana - Journal for Brazilian Studies, London, v. 5. n. 1, p. 230-253, 2016.

FEARNSIDE, P. M. A água de São Paulo e a floresta amazônica. Ciência Hoje, Rio de Janeiro, v. 34, n. 203, p. 63-65, 2004.

GREENPEACE BRASIL. Governador do AM enfraquece gestão de UC's do estado, 2015. Disponível em: http://www.greenpeace.org/brasil/pt/Noticias/Governador-do-AM-enfraquece-gestao-de-UCs-do-estado/. Acesso em: 23 mar. 2017.

IBGE - INSTITUTO BRASILEIRO DE GEOGRAFIA E ESTATÍSTICA. Censo Demográfico de 2010. Disponível em: http:/www.ibge.gov.br/ home/estatistica/populacao/censo2010/default.shtm. Acesso em: 10 mar. 2017.

OLIVEIRA, R. S.; TSAMAREN, L. M. S. Projeto Jacitara: uma iniciativa comunitária de valorização cultural. In: SILVEIRA, E. D.; CAMARGO; S. A. F. Socioambientalismo de fronteiras: sobre uma Amazônia Múltipla. Curitiba: Juruá, 2017. p. 91-110.

ROESSING NETO, E. Análise da relação entre a Lei n. 3135/2007 do Estado do Amazonas e o Direito Internacional à luz da doutrina antiformalista francesa. Florianópolis: UFSC, 2009. 
SANTILLI, M. Terras indígenas e crise climática. In: VALLE, R. S. T. Desmatamento evitado (REDD) e povos indigenas: experiências, desafios e oportunidades no contexto amazônico. Brasília/São Paulo: Instituto Socioambiental e Forest Trends, 2010. p. 9-20.

SANTOS, F. P. Gestão de UCs no Amazonas: avanços e desafios para a conservação ambiental. Revista Geonorte, Manaus, v. 8, n. 1, p. 102-124, 2013.

SERRAO, E. A. O. et al. Evaluation the drought 2005 and 2010 in Amazon: analysis the Solimões Basin. Revista Geográfica Acadêmica, Boa Vista, v. 9, n. 2, p. 5-16, 2015.

SOARES, T. J.; HIGUCHI, N. A convenção do clima e a legislação brasileira pertinente, com ênfase para a legislação ambiental no Amazonas. Acta Amazonica, Petrópolis, v. 36, n. 4, p. 573-580, 2006.

VIANA, V. M. Bolsa Floresta: um instrumento inovador para a promoção da saúde em comunidades tradicionais na Amazônia. Estudos Avançados, São Paulo, v. 22, n. 64, p. 143-153, 2008.

Artigo recebido em: 26/08/2019.

Artigo aceito em: 04/03/2020.

\section{Como citar este artigo (ABNT):}

CAMARGO, S. A. F.; GOMIDE, P. H.; CAMARGO, T. R. L. Mudanças climáticas e projetos de prestação de serviços ambientais em terras indígenas no Amazonas. Veredas do Direito, Belo Horizonte, v. 17, n. 37, p. 323-345, jan.-abr. 2020. Disponível em: http://revista.domhelder.edu.br/ index.php/veredas/article/view/1503. Acesso em: dia mês. ano. 